\title{
A unified global investigation on the spectral effects of soiling losses of PV glass substrates: preliminary results
}

\author{
Leonardo Micheli ${ }^{1,2^{*}}$, Eduardo F. Fernández ${ }^{3}$, Greg P. Smestad ${ }^{4}$, Hameed Alrashidi ${ }^{5}$, Nabin Sarmah ${ }^{6}$, Nazmi \\ Sellami $^{7}$, Ibrahim A. I. Hassan ${ }^{8}$, Amal Kasry ${ }^{9}$, Gustavo Nofuentes ${ }^{3}$, Neeru Sood ${ }^{10}$, Bala Pesala ${ }^{11,12}$, S. \\ Senthilarasu ${ }^{5}$, Florencia Almonacid ${ }^{3}$, K.S. Reddy ${ }^{13}$, Matthew Muller ${ }^{1}$, Tapas K. Mallick ${ }^{5}$ \\ ${ }^{1}$ National Renewable Energy Laboratory, Golden (CO), USA \\ ${ }^{2}$ Colorado School of Mines, Golden (CO), USA \\ ${ }^{3}$ University of Jaén, Jaén, Spain \\ ${ }^{4}$ Sol Ideas Technology Development, San José (CA), USA \\ ${ }^{5}$ University of Exeter, Penryn, UK \\ ${ }^{6}$ Tezpur University, Tezpur, India \\ ${ }^{7}$ Robert Gordon University, Aberdeen, UK \\ ${ }^{8}$ South Valley University, Qena, Egypt \\ ${ }^{9}$ British University in Egypt, El Sherouk City, Egypt \\ ${ }^{10}$ BITS Pilani, Dubai Campus, Dubai, UAE \\ ${ }^{11}$ Academy of Scientific and Innovative Research, Chennai, India \\ ${ }^{12}$ CSIR-Central Electronics Engineering Research Institute, Chennai, India \\ ${ }^{13}$ Indian Institute of Technology Madras, Chennai, India
}

\begin{abstract}
The present work reports on the initial results of an international collaboration aiming to investigate the spectral effects of soiling losses. Identical glass coupons have been exposed outdoors for eight weeks in different locations worldwide, and weekly direct and hemispherical transmittance (T\%) measurements are compared. Maximum losses as high as $\mathbf{7 \%}$ and $50 \%$ in hemispherical and direct transmittance, respectively, have been found during the 8-week outdoor exposure. At the end of the data collection, a preliminary analysis of the spectral impact of soiling has been performed. The results show that the blue end of the spectrum is more affected and that lower hemispherical $\mathrm{T} \%$ correlate to larger area covered by particles.

Index Terms - photovoltaic systems, reliability, optical losses, soiling.
\end{abstract}

\section{INTRODUCTION}

The accumulation of dust is one of the major concerns for photovoltaic (PV) systems since it reduces the sunlight transmitted by the glass surface and, thus, the energy converted by the modules. The dust composition and the particle size play a fundamental role in the impact of soiling losses [1], [2]. Several works have analyzed the relation between the dust and the soiling losses in different locations [3]-[5]. All these analysis are generally site-specific or highly regionalized. Other works have instead analyzed the effect of artificially deposited dust [6], [7]. This work presents the preliminary results of an international collaboration among academic and research institutes and private partners that aims to investigate the spectral effects of soiling naturally deposited on PV glasses installed at various locations worldwide.

\section{MATERIALS AND METHODS}

Tests have been conducted at eight locations worldwide, listed in Table I, chosen to represent a wide variety of climates and environmental conditions. Each partner used a spectrophotometer to weekly measure the change in transmission due to the accumulation of soiling. Seven identical $4 \mathrm{~cm} \times 4 \mathrm{~cm}$ sized and $3 \mathrm{~mm}$-thick Diamant ${ }^{\circledR}$ lowiron glass from Saint-Gobain Glass were shipped to each location. Coupons were numbered from 0 to 6: six of them (coupons 1 to 6) were installed outdoors, at zero tilt angle, using the supporting structure shown in Fig. 1. Coupon 0 was instead kept in a safe, dust-free container and used to calibrate and compare the different spectrophotometers.

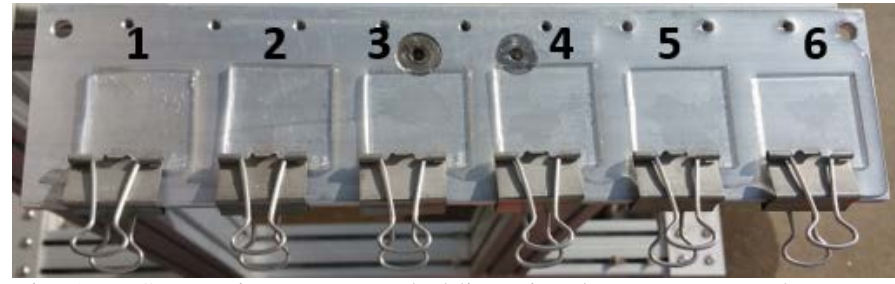

Fig. 1. Supporting structure holding six glass coupons. These are held with binder clips on a horizontally-mounted aluminum plate. Weekly transmittance measurements are taken for coupons 1, 2 and

3 , whereas coupons 4, 5 and 6 have been used for dust characterization.

Weekly transmission measurements were taken on coupons 1, 2 and 3. Coupon 1 was cleaned weekly, coupon 2 was 
cleaned every 4 weeks (twice during the data collection) and coupon 3 was never cleaned. A dry cleaning is performed by using a microfiber cleaning cloth. Coupons 4,5 and 6 were not cleaned nor moved until the end of the data collection, since they will be used for the dust characterization analyses. Daily weather data and, where available, mean daily concentrations of particulate matter (PM) have been recorded.

\section{RESULTS}

\section{A. Impact of soiling on broadband hemispherical transmittance}

The data collection commenced in January 2017. The average and maximum weekly loss in hemispherical transmittance is reported in Table II. The results obtained by the measurements performed in Golden, Colorado, USA, are shown in Fig. 2. Coupon 1, cleaned every week, shows a weekly average reduction of $0.7 \%$ in hemispherical transmittance. In contrast, this value increases to $1.3 \%$ in Chennai. This result agrees with the expectations: mean daily concentrations of $\mathrm{PM}_{2.5}$ of $11 \mu \mathrm{g} / \mathrm{m}^{3}$ and $41 \mu \mathrm{g} / \mathrm{m}^{3}$ were recorded in January 2017 from monitoring stations nearby Golden and Chennai, respectively. At the end of the data collection, Coupon 3 had lost 1.7\% in Golden and 6\% in Chennai respectively. During the same time period, maximum losses of 7\% have been registered in Jaén, because of Saharan dust transported onto the town during Week 3 and week 5.

Fig. 2 shows that the effect of the deposits on soiled coupon 3 does not necessarily increase at the same rate as coupon 1 , which is cleaned weekly. Indeed, differently soiled coupons can be differently impacted by rainfalls: if soiling has been accumulating for some time, it might be more difficult to wash. This is found to happen in all the locations investigated.

\section{B. Impact of soiling on broadband direct transmittance}

As expected, higher losses have been found when direct transmittance is considered instead of hemispherical. Figure 3 shows the results of the weekly measurements conducted on Coupon 3 in Golden, CO. When compared in the same wavelength range (500 $\mathrm{nm}$ to $1100 \mathrm{~nm}$ ), the direct transmittance is found to drop by $6 \%$ in 6 weeks, while the loss in hemispherical transmittance is limited to $1.5 \%$.

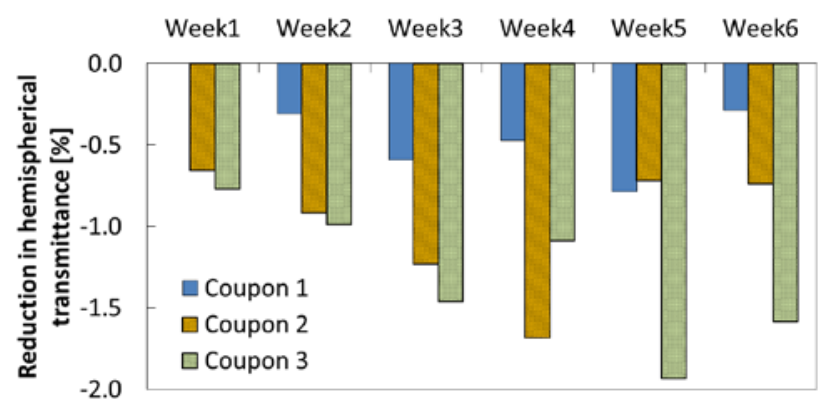

Fig. 2. Progressive absolute drop in hemispherical transmittance, compared to the initial conditions, registered in Golden, CO. Transmittance is obtained by averaging the data recorded between 200 and $1100 \mathrm{~nm}$, with a $1 \mathrm{~nm}$ step. Coupon 1 was manually cleaned every week and coupon 2 was cleaned on week 4.

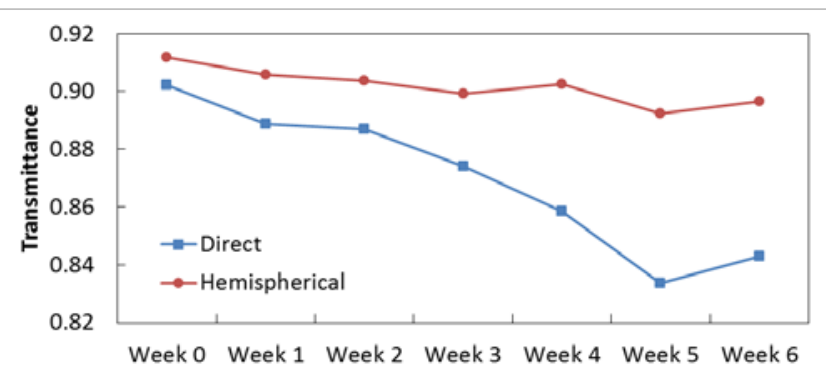

Fig. 3. Direct and hemispherical transmittance of coupon 3 in Golden. Wavelengths between 500 and $1100 \mathrm{~nm}$ have been averaged.

Average weekly and maximum losses recorded at three sites are shown in Table III. In El Shorouk City, weekly losses as high as $20 \%$ in direct transmittance have been registered. In Tezpur, a drop of $23 \%$ in direct transmittance was measured on coupon 3 after the longest dry period (2 weeks). The measurements taken at the end of the dry period, week 5, are shown in Fig. 4. Coupons 1 and 2 (both cleaned in week 4) have similar transmittance, although, they both show a drop in transmittance between 8 and 10\%, compared to coupon 0 , after only one week.

TABLE I

List OF MONITORED LOCATIONS AND Climate ClassificATIONS, SOURCED FROM [9].

\begin{tabular}{|c|c|c|c|}
\hline City, Country & Coordinates & Measured transmittance & Climate classification \\
\hline Chennai, India & $13.08,80.27$ & Hemispherical & Equatorial savannah with dry winter (Aw) \\
\hline Dubai, UAE & $28.36,75.59$ & Hemispherical & Desert climate (Bwh) \\
\hline El Shorouk City, Egypt & $30.12,31.61$ & Direct & Desert climate (Bwh) \\
\hline Golden (CO), USA & $39.74,-105.18$ & Hemispherical and Direct & Snow climate, fully humid (Dfb) \\
\hline Jaén, Spain & $37.79,-3.78$ & Hemispherical & Warm temperate climate with dry summer (Csa) \\
\hline Penryn, UK & $50.17,-5.13$ & Hemispherical & Warm temperate climate, fully humid (Cfb) \\
\hline San José (CA), USA & $37.29,-121.91$ & Hemispherical & Warm temperate climate with dry summer (Csb) \\
\hline Tezpur, India & $26.70,92.83$ & Direct & Warm temperate climate with dry winter (Cwa) \\
\hline
\end{tabular}


TABLE II

ABSOLUTE AVERAGE AND MAXIMUM WEEKLY LOSS IN

BROADBAND HEMISPHERICAL TRANSMITTANCE. WEEKLY

LOSSES CALCUlated For COUPON 1, MAXIMUM LOSSES

CALCULATED FOR COUPON 3. TRANSMITTANCE WAS

MEASURED WITH DIFFERENT SPECTROPHOTOMETERS AT

EACH SITE.

\begin{tabular}{|c|c|c|}
\hline City, Country & $\begin{array}{c}\text { Absolute average } \\
\text { weekly loss (\%) }\end{array}$ & $\begin{array}{c}\text { Maximum loss } \\
(\%)\end{array}$ \\
\hline Chennai, India & -1.3 & -7.8 \\
\hline Golden (CO), USA & -0.7 & -2.0 \\
\hline Jaén, Spain & -3.2 & -7.0 \\
\hline Penryn, UK & -0.8 & -2.3 \\
\hline San José (CA), USA & N.A. & -3.7 \\
\hline
\end{tabular}

\section{Impact of soiling on spectral transmittance}

At the end of the data collection, coupons 4, 5 and 6 have been shipped to NREL from each location, in order to perform the analysis using the same instrument. The variety of soiling conditions in this project allows for a general analysis of spectral losses. The normalized hemispherical transmittance spectra in the visible and NIR regions of the spectrum for coupon 5 are shown in Fig. 5 for the end of the outdoor exposure period. The transmittance is divided by that recorded for coupon 0 at each location; this way, the effect of soiling on the transmission at each wavelength can be analyzed independently of the optical nature of the glass. The initial results show that soiling has a higher impact on the blue than on the red end of the spectrum, independently of the location and of the amount of losses. This is in agreement with the conclusions of Ref. [6] where coupons artificially soiled with dust collected in Kuwait were studied.
TABLE III

ABSOLUTE AVERAGE AND MAXIMUM WEEKLY LOSS IN

BROADBAND DiRECT TRANSMITTANCE. WEEKLY LOSSES

CALCUlated For COUPON 1, MAXIMUM LOSSES

Calculated For Coupon 3. TRANSMitTanCE WAS

MEASURED WITH DIFFERENT SPECTROPHOTOMETERS AT EACH SITE

\begin{tabular}{|c|c|c|}
\hline City, Country & $\begin{array}{c}\text { Absolute average } \\
\text { weekly loss (\%) }\end{array}$ & Maximum loss (\%) \\
\hline Golden (CO), USA & -1.4 & -6.9 \\
\hline El Shorouk City, Egypt & -6.0 & -46.9 \\
\hline Tezpur, India & -11.9 & -23.6 \\
\hline
\end{tabular}

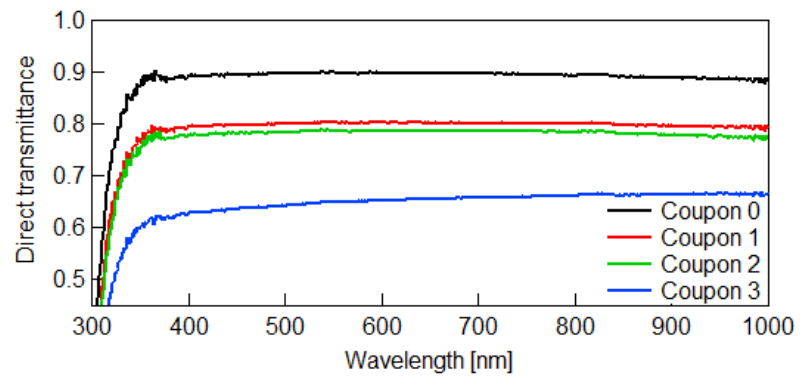

Fig. 4. Direct transmittance of coupons 1, 2, 3 in Tezpur, India, measured at week 5, after two dry weeks. Coupons 1 and 2 have similar transmittance since both have been cleaned at week 4 .

For a better understanding of the spectral behavior for mild soiling conditions, the hemispherical transmittance of five sites have also been reported in Fig. 6, using a different y-axis scale. In this case, the data have been processed using a local regression technique to remove noise. $\mathrm{R}^{2}$ between original and smoothed data is kept above 0.91. All the sites show similar trends at large wavelengths, whereas different behaviors have been found at wavelengths shorter than $500 \mathrm{~nm}$. Indeed, Golden (CO) and San Jose (CA) have similar broadband hemispherical transmittance and the \%T overlaps between 500 $\mathrm{nm}$ and $1000 \mathrm{~nm}$. The same happens for Jaen and Tezpur. Below that value, the curves diverge, having Golden (CO) and Tezpur a steeper drop occurring at shorter wavelength than San José (CA) and Jaén. This result suggests that other factors might have an impact on the spectral losses of soiling.

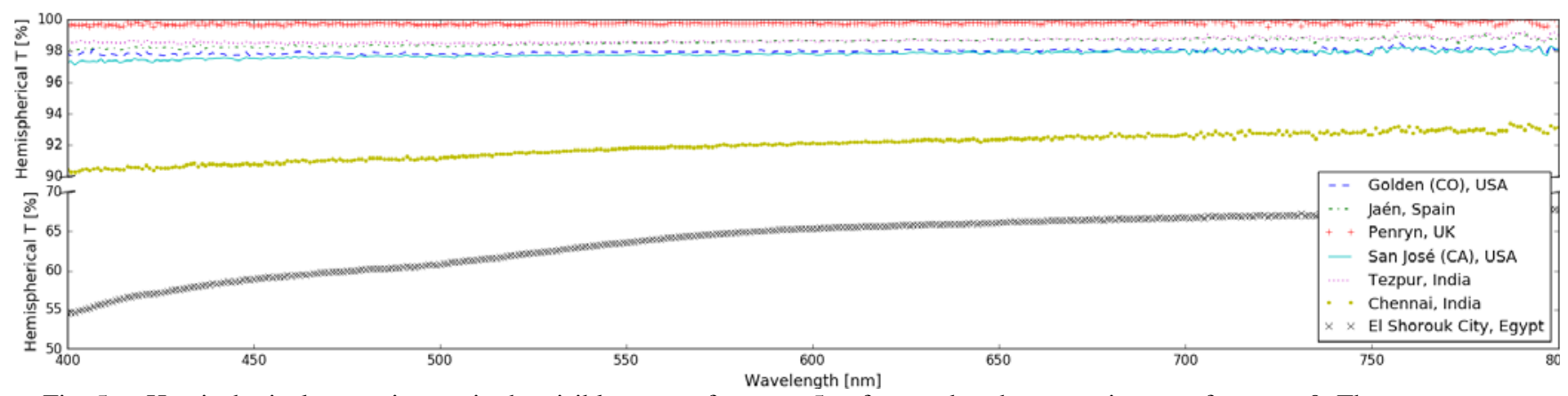

Fig. 5. Hemispherical transmittance in the visible range of coupon 5, referenced to the transmittance of coupon 0 . The spectra were measured using a PerkinElmer Lambda $1050 \mathrm{UV} /$ Vis spectrophotometer with a $150 \mathrm{~mm}$ integrating sphere. 
TABLE IV

Broadband Hemispherical Transmittance (300-2500 Micrometers), Average Particle Area, and Percentage of THE SURfaCe Covered by Particles, Measured at The End of The Data Collection. Unsoiled Glass TRANSMITTANCE Is $90.4 \%$

\begin{tabular}{|c|c|c|c|}
\hline City, Country & Hemispherical transmittance [\%] & Average particle area $\left[\mu m^{2}\right]$ & Area coverage [\%] \\
\hline Chennai, India & 84.2 & $132-168$ & $5.1-8.3$ \\
\hline El Shorouk City, Egypt & 63.1 & $110-194$ & $21.3-22.8$ \\
\hline Golden (CO), USA & 88.8 & $55-100$ & $1.7-2.4$ \\
\hline Jaén, Spain & 89.3 & $33-92$ & $1.3-1.4$ \\
\hline Penryn, UK & 90.1 & N.A. & N.A. \\
\hline San José (CA), USA & 88.5 & $206-220$ & 1.9 \\
\hline Tezpur, India & 89.6 & $47-60$ & $0.3-0.4$ \\
\hline
\end{tabular}

From a visual inspection of the photographs in Fig. 7, it can be seen that a larger area density of particles was collected in Egypt than for any other location. This is in agreement with the results of the analysis conducted using the image processing program ImageJ [8] summarized in Table IV. The larger density may be responsible for its higher transmission losses. Indeed, a linear correlation, with $\mathrm{R}^{2}$ higher than 0.99 , is found by comparing the percentage area covered by particles to the hemispherical transmission. This means that, despite the spectral losses, the broadband hemispherical transmission could be directly obtained from the covered area, independently of dust type and composition. Due to the low amount of soiling that occurred at Penryn, UK site, no particle characterization was performed using optical microscopy.

\section{CONCLUSIONS}

Soiling is an issue affecting PV systems worldwide and depends on a number of site-specific factors. The main aim of this work is the comparison of naturally-accumulated soiling on PV glass at diverse regions around the world. Identical glass coupons have been exposed and cleaned at fixed time intervals. Transmissivity has been measured weekly and the preliminary results highlight similarities and differences. Weekly broadband losses are as high as $3 \%$ and $12 \%$ in hemispherical and direct transmission, respectively, and are greater in the blue and UV portion of the spectrum. From a preliminary analysis of the data, it has been found that there is a linear correlation between the area covered by particles and the broadband hemispherical transmittance, independently of the location of soiling. A more detailed investigation of the spectral losses and their relation to the soiling type, particle size and composition should be pursued in the future.

\section{ACKNOWLEDGEMENTS}

This work is part of the "Global investigation on the spectral effects of soiling losses" project, conceived and financed under the EPSRC SUPERGEN SuperSolar Hub's "International and industrial engagement fund". This work was partly supported by the U.S. Department of Energy under Contract No. DE-AC36-08GO28308 with Alliance for Sustainable Energy, LLC, the Manager and Operator of the National Renewable Energy Laboratory.

The U.S. Government retains and the publisher, by accepting the article for publication, acknowledges that the U.S. Government retains a nonexclusive, paid-up, irrevocable, worldwide license to publish or reproduce the published form of this work, or allow others to do so, for U.S. Government purposes.

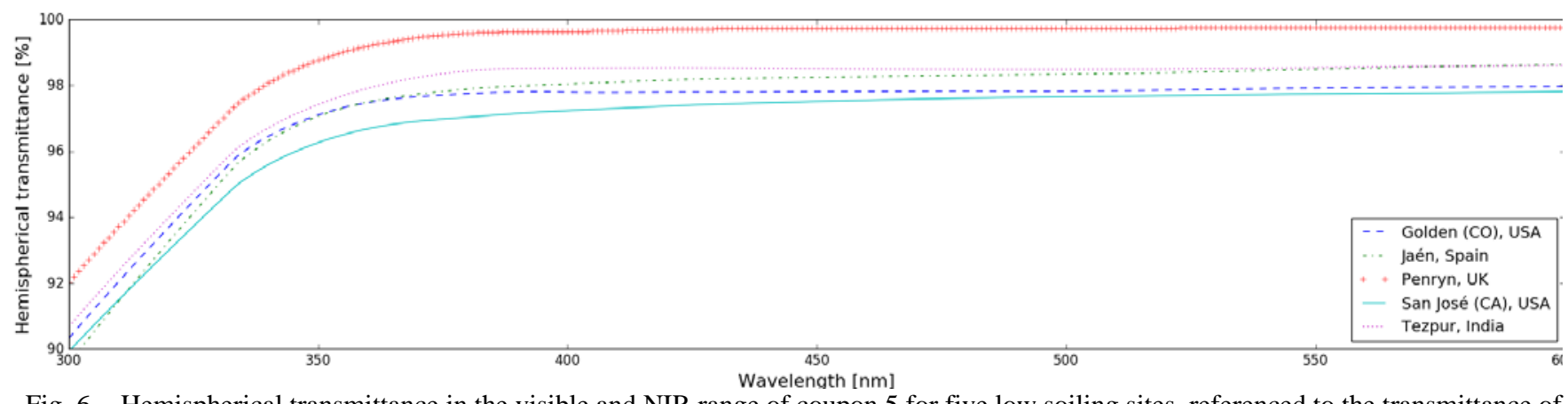

Fig. 6. Hemispherical transmittance in the visible and NIR range of coupon 5 for five low soiling sites, referenced to the transmittance of coupon 0. The spectra were measured using a PerkinElmer Lambda 1050 UV/Vis spectrophotometer with a $150 \mathrm{~mm}$ integrating sphere and processed using a local regression technique to remove noise. 


\section{REFERENCES}

[1] T. Sarver, A. Al-Qaraghuli, and L. L. Kazmerski, “A comprehensive review of the impact of dust on the use of solar energy: History, investigations, results, literature, and mitigation approaches,” Renew. Sustain. Energy Rev., vol. 22, pp. 698-733, 2013.

[2] S. C. S. Costa, A. Sonia, A. C. Diniz, and L. L. Kazmerski, "Dust and soiling issues and impacts relating to solar energy systems : Literature review update for 2012 - 2015," Renew. Sustain. Energy Rev., vol. 63, pp. 33-61, 2016.

[3] W. Javed, Y. Wubu likasimu, B. Figgis, and B. Guo, "Characterization of dust accumulated on photovoltaic panels in Doha, Qatar,” Sol. Energy, vol. 142, pp. 123-135, 2017.

[4] T. Khatib, H. Kazem, K. Sopian, F. Buttinger, W. Elmenreich, and A. Said Albusaidi, "Effect of Dust Deposition on the Performance of Multi-Crystalline Photovoltaic Modules Based on Experimental Measurements," Int. J. Renew. Energy Res., vol. 3, no. 4, pp. 850-853, 2013.
[5] P. D . Burton, L. Boyle, J. J. M. Griego, and B. H. King, "Quantification of a Minimum Detectable Soiling Level to Affect Photovoltaic Devices by Natural and Simulated Soils,” IEEE J. Photovoltaics, vol. 5, no. 4, pp. 1143-1149, 2015.

[6] H. Qasem, T. R. Betts, H. Müllejans, H. AlBusairi, and R. Gottschalg, "Dust-induced shading on photovoltaic modules," Prog. Photovoltaics Res. Appl., vol. 22, no. 2, pp. 218-226, 2014.

[7] P. D. Burton and B. H. King, "Artificial soiling of photovoltaic module surfaces using traceable soil components," Conf. Rec. IEEE Photovolt. Spec. Conf., pp. 1542-1545, 2013.

[8] M. D. Abramoff, P. J. Magalhaes, and S. J. Ram, "Image Processing with ImageJ," Biophotonics Int., vol. 11, no. 7, pp. 36-42, 2004.

[9] M. Kottek, J. Grieser, C. Beck, B. Rudolf, and F. Rubel, "World map of the Köppen-Geiger climate classification updated," Meteorol. Zeitschrift, vol. 15, no. 3, pp. 259-263, 2006. 

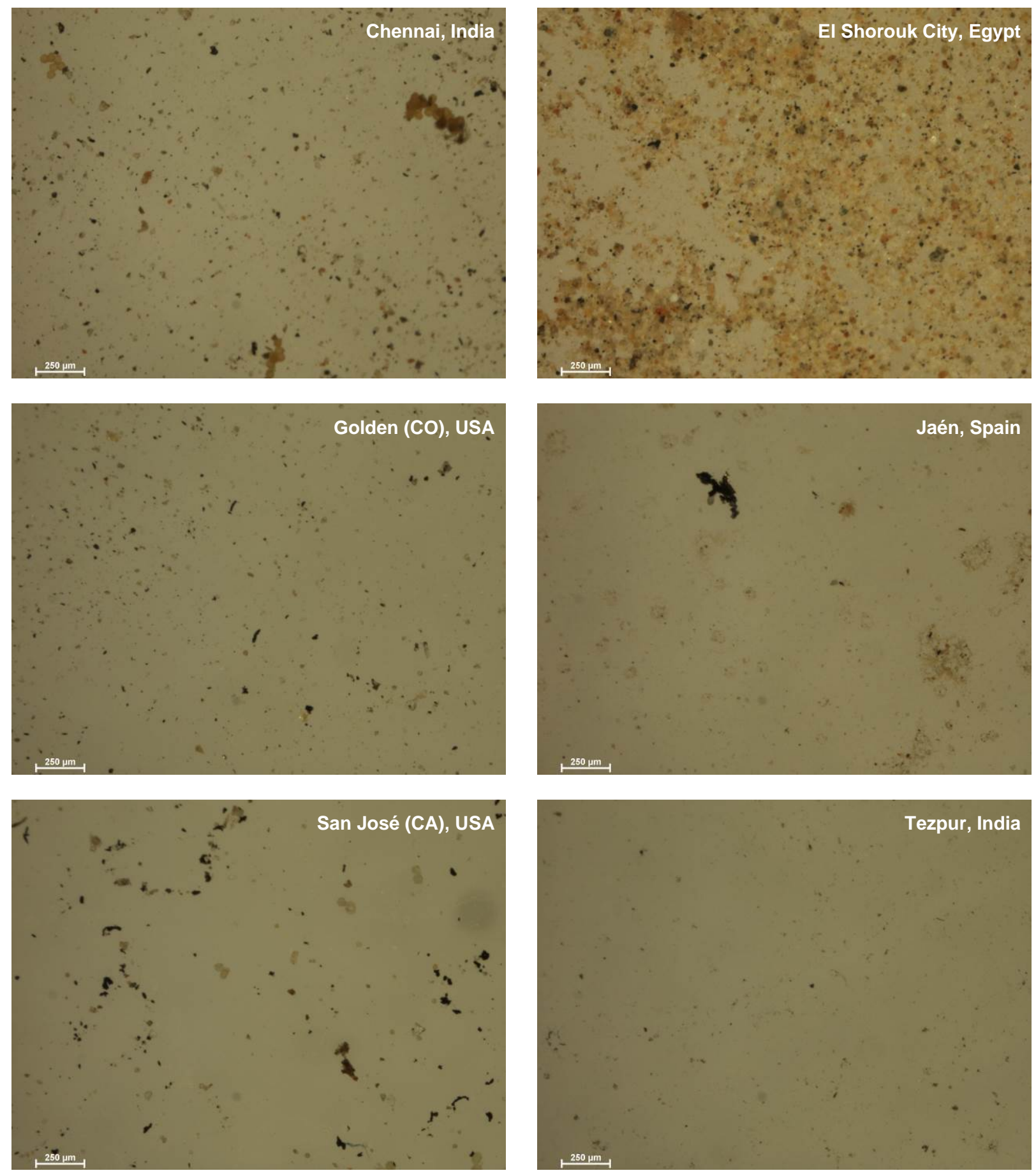

Fig. 7. Microscope pictures of six coupons at the end of the data collection. Pictures have been taken using a Nikon SMZ 1500 stereomicroscope at a magnitude of $5 \times$ : the scale bar on the bottom left represents a length of $250 \mu \mathrm{m}$. 